\title{
Research on Numerical Simulation of 3D Leakage Magnetic Field and Short-circuit Impedance of Axial Dual-low-voltage Split-winding Transformer ${ }^{*}$
}

\author{
Yan Li, Longnv Li, Yongteng Jing, Fangxu Han \\ Research Institute of Special Electrical Machines, Shenyang University of Technology, Shenyang, China \\ Email: lilongnv620@163.com
}

Received March, 2013

\begin{abstract}
It is difficult to accurately calculate the short-circuit impedance, due to the complexity of axial dual-low-voltage split-winding transformer winding structure. In this paper, firstly, the leakage magnetic field and short-circuit impedance model of axial dual-low-voltage split-winding transformer is established, and then the 2D and 3D leakage magnetic field are analyzed. Secondly, the short-circuit impedance and split parallel branch current distribution in different working conditions are calculated, which is based on field-circuit coupled method. At last, effectiveness and feasibility of the proposed model is verified by comparison between experiment, analysis and simulation. The results showed that the 3D analysis method is a better approach to calculate the short-circuit impedance, since its analytical value is more closer to the experimental value compared with the $2 \mathrm{D}$ analysis results, the finite element method calculation error is less than $2 \%$, while the leakage flux method maximum error is $7.2 \%$.
\end{abstract}

Keywords: Split-winding Transformer; Short-circuit Impedance; Field-circuit Coupled; Current Distribution

\section{Introduction}

Short-circuit impedance is the important technical parameter of power transformer [1,2]. The value of shortcircuit impedance can influence the cost, efficiency, voltage regulation, mechanical strength, short-circuit current of transformer, so the deviation between measured value and rated value when the transformer leave factory is very strict. Split-winding transformer splits one winding into two ones, when one winding is short circuit it can increase the impedance, it's the effective and economy method to restrict the shot-circuit current. The application of split-winding transformer is used more and more widely following with the increase of unit capacity and system capacity [3-6]. So calculation of short-circuit impedance accurately in split-winding transformer is important in transformer design.

2D and 3D calculation model are established for a axial dual-low-voltage split-winding transformer which type is SFFZ10-88000 kVA/220 kV based on rational simplification and assumption. Apply field-circuit coupled method to compute and analysis the leakage magnetic field and short-circuit impedance, it could be used as the starting point for studying the load short circuit

${ }^{*}$ This work was supported by NSFC, under Project 51177103 and Program for LNIRT in University (LT2011002). current and distribution of high voltage parallel road current. At last, finite element, computing and experimental values are contrastive analyzed, then the finiteelement analysis is verified to be proper and more veracity.

\section{Basic Parameter and Calculation Model of Split-winding Transformer}

The structure diagram of axial dual-low-voltage splitwinding transformer is shown in Figure 1.

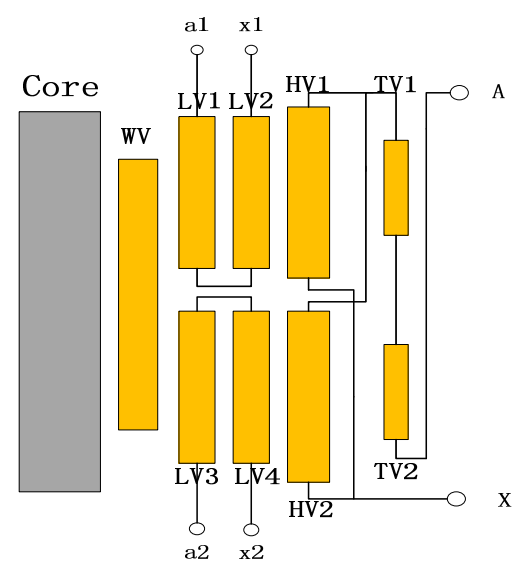

Figure 1. Structure diagram of winding. 
The arrangement of winding is core---balanced winding---low voltage winding---high voltage winding ---regulating winding. Low voltage winding break up into four equality rated capacity (LV1, LV2, LV3, LV4). High voltage winding adopt inlet line from central section, the two parts (HV1, HV2) are in parallel then connected in series with regulating winding (TV1, TV2). Regulating winding all accessing is maximum tap, reverse accessing is minimum tap. The low and high voltage winding of transformer are all $\mathrm{Y}$ connection, a balanced winding is needed to provide access of third harmonic current for enhancing waveform quality. The basic parameter of split-winding transformer is shown in Table 1. $3 \mathrm{D}$ calculation model of split-winding transformer is shown in Figure 2.

The assumption conditions are shown as follows:

1) The $1 / 2$ model of whole transformer model is established in order to reduce the computational time;

2) The eddy currents and their influence on windings are neglected;

3) The currents in the windings are equally distributed along the cross section;

4) All field quantity sinusoidal variation with time, do not consider the high-order harmonic.

The diagram of external circuit that calculating the shortcircuit impedance of transformer based on field-circuit coupled method is shown in Figure 3. Figure 3(a) shows the equivalent circuit diagram of crossing, Figure 3(b) shows the equivalent circuit diagram of semi-crossing.

Table 1. Basic Parameter of Split-winding Transformer.

\begin{tabular}{lc}
\hline \multicolumn{1}{c}{ Parameter } & Value \\
\hline Rated current of high voltage winding & $109.95 \mathrm{~A}$ \\
Rated current of low voltage winding & $2419.4 \mathrm{~A}$ \\
Rated current of regulating winding & $219.9 \mathrm{~A}$ \\
Rated current of balanced winding & $936.5 \mathrm{~A}$ \\
Turns of high voltage winding & 773 \\
Turns of low voltage winding & LV1,LV3(18),LV2,LV4(19) \\
Turns of regulating winding & 40 \\
Turns of balanced winding & 64 \\
\hline
\end{tabular}

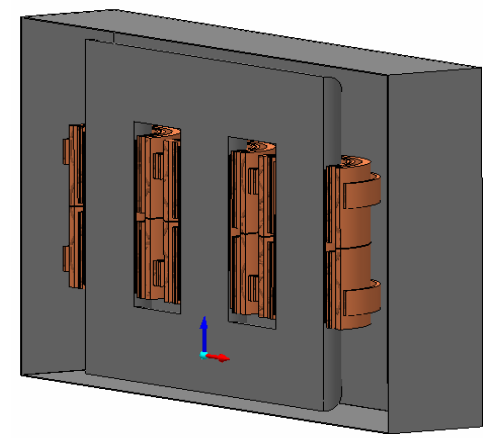

Figure 2. Model of split-winding transformer.
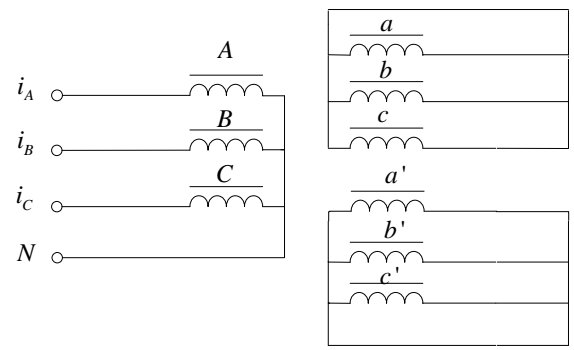

(a) Equivalent circuit diagram of crossing

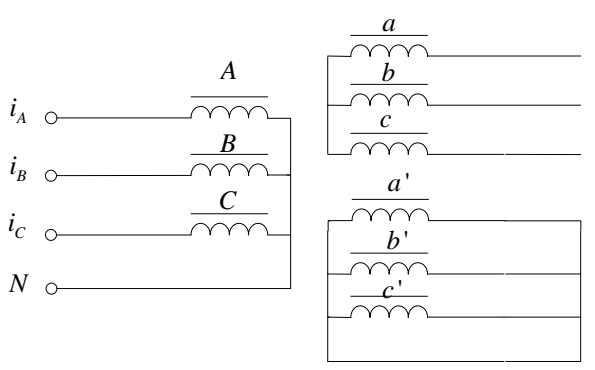

(b) Equivalent circuit diagram of semi-crossing

Figure 3. Equivalent circuit diagram.

$i_{A}, i_{B}, i_{C}$ is the three-phase symmetrical current source with internal impedance at the secondary side of the transformer. $A, B, C$ is the secondary winding consist of $\mathrm{HV}$ and TV. $a, b, c$ is the primary winding consist of LV.

\section{Calculation of Short-circuit Impedance}

Calculation of short-circuit impedance percentage using analytical method can be governed by following equation:

$$
U_{K}=\frac{49.6 f \cdot I_{N} W \sum D \rho K}{e_{t} H \times 10^{6}}
$$

where $e_{t}$ is every turn potential, $I_{N}$ is rated phase current of winding, $W$ is total number of turns, $H$ is average reactance height of coil, $K$ is additional reactance coefficient, $\rho$ is low-type coefficient, $\sum D$ is leakage magnetic area.

When calculate the short circuit impedance of transformer by the finite element method based on field-circuit coupled, energy of magnetic field stored in transformer is transformed from external source during setting up the magnetic field. Calculate the distribution of magnetic can obtain the energy of magnetic field stored in transformer [7,8]. When there is the current $I_{N}$ in winding, energy of magnetic field $W_{m}$ is:

$$
W_{m}=\frac{1}{2} L I_{N}^{2}
$$

where $W_{m}$ is magnetic field energy, $L$ is inductance of winding, $I_{N}$ is phase current. 
When resistive component of the short-circuit impedance can be ignored, the short-circuit impedance of corresponding rated current $I_{N}$ is:

$$
Z_{K}=\omega \cdot L=2 \omega W_{m} / I_{N}{ }^{2}
$$

where $Z_{K}$ is short-circuit impedance (leakage reactance), $\omega$ is angular frequency of power source.

Percentage of short-circuit impedance is shown as:

$$
U_{K}=\frac{Z_{K}}{Z_{N}}=\frac{\omega L I_{N}}{U_{N}}=\frac{4 \pi f W_{m}}{V A}
$$

Where $U_{K}$ is percentage of short-circuit impedance, $f$ is frequency, $V A$ is capacity of single phase when transformer working under rated operating condition.

\section{Analysis of Calculation Results}

The short-circuit impedance of axial dual-low-voltage split-winding transformer is calculated and analyzed though analytical method, 2D and 3D finite element method. The distribution of leakage magnetic vector when the transformer is working under crossing and semicrossing condition are respectively shown in Figure 4(a) and Figure 4(b).

The comparison of results about the short-circuit impedance of split-winding transformer working under different conditions are shown in Table 2. In this table, low-up is LV1 and LV2 in the structure diagram, lowdown is LV3 and LV4 in the structure diagram, $Z_{d}$ is the short-circuit impedance of crossing, $Z_{B}$ is the short-circuit impedance of semi-crossing.

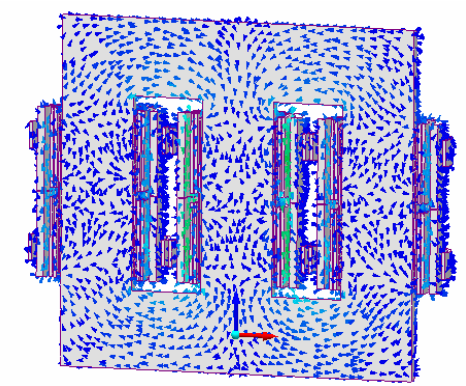

(a) Leakage magnetic vector distribution of crossing

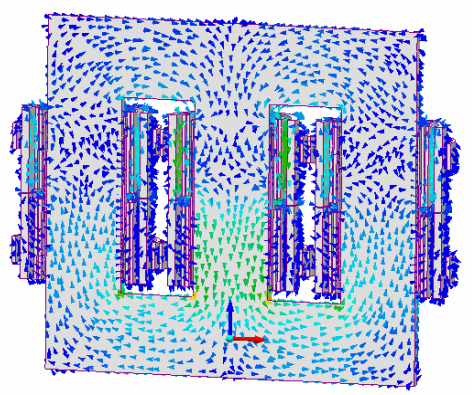

(b) Leakage magnetic vector distribution of semi-crossing

Figure 4. 3D leakage magnetic field distribution (rated tap).
Table 2. Short-circuit Impedance Results of Split- winding Transformer (\%).

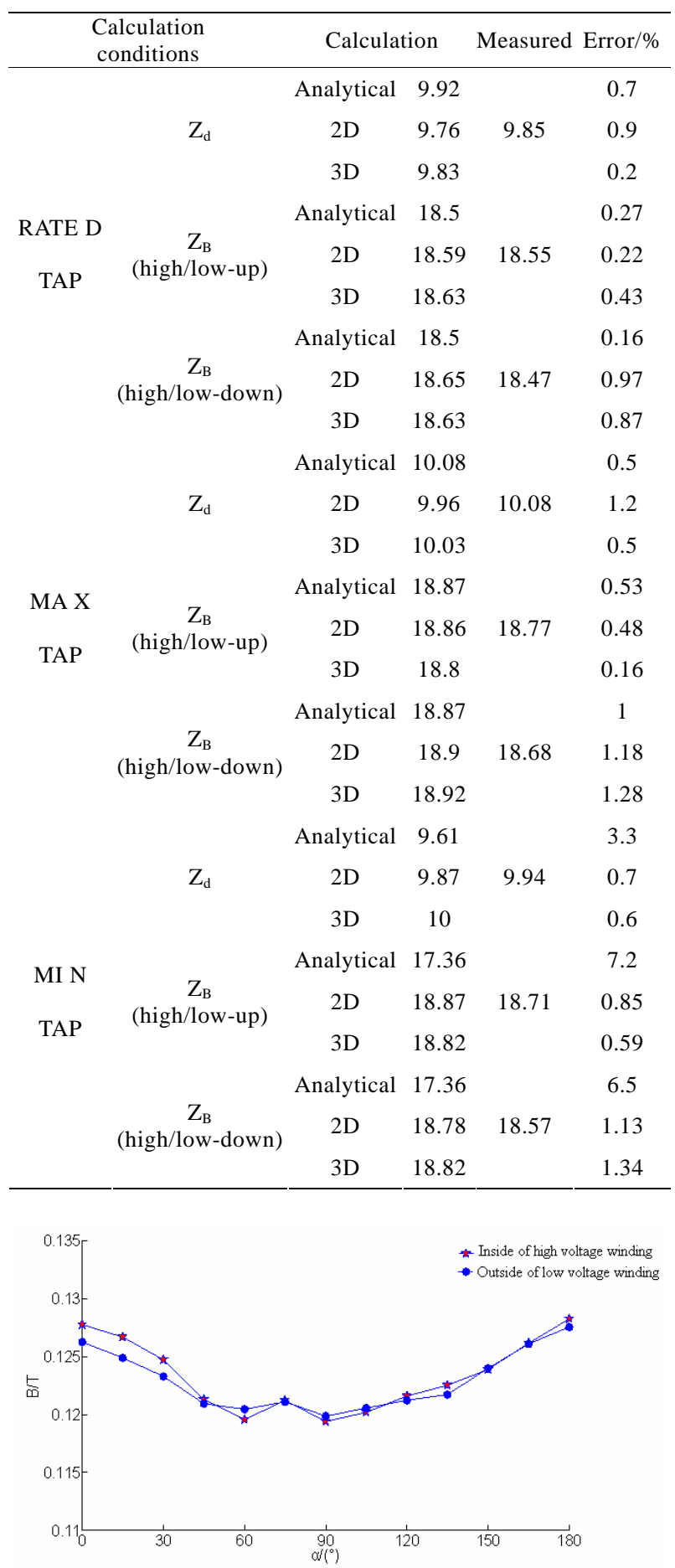

Figure 5. End winding magnetic flux density distribution along circle direction.

The distribution of magnetic flux density along circle direction of upper end of the winding under crossing condition is shown in Figure 5. The distribution of magnetic flux density is uneven along the circle direction of 
Table 3. Current calculation of HV parallel branch (-show phase contrast).

\begin{tabular}{cccc}
\hline \multicolumn{2}{c}{ Calculation conditions } & $\begin{array}{c}\text { High voltage } \\
\text { up/A }\end{array}$ & $\begin{array}{c}\text { High voltage } \\
\text { down/A }\end{array}$ \\
\hline \multirow{4}{*}{ Rated tap } & $\mathrm{Z}_{\mathrm{d}}$ & 109.95 & 110.14 \\
& $\mathrm{Z}_{\mathrm{B}}$ (high/low-up) & 111.02 & -1.08 \\
& $\mathrm{Z}_{\mathrm{B}}$ (high/low-down) & -1.11 & 111.02 \\
\multirow{4}{*}{ Max tap } & $\mathrm{Z}_{\mathrm{d}}$ & 104.62 & 104.88 \\
& $\mathrm{Z}_{\mathrm{B}}$ (high/low-up) & 108.62 & -3.66 \\
& $\mathrm{Z}_{\mathrm{B}}$ (high/low-down) & -3.67 & 108.62 \\
\multirow{4}{*}{ Min tap } & $\mathrm{Z}_{\mathrm{B}}$ (high/low-up) & 129.13 & 129.67 \\
& $\mathrm{Z}_{\mathrm{B}}$ (high/low-down) & 8.45 & 8.46 \\
\hline
\end{tabular}

winding from the figure, the magnetic flux density in the core window is larger than that out of the core window.

The comparative analysis of the analytical method, 2D finite element method, 3D finite element method and measured values shows that the 3D finite element calculation value is more close to the measured value. Due to short-circuit impedance is decided by the value and regularity of distribution of leakage magnetic field, analytical method can not calculate the leakage magnetic accurately. 2D finite element method can not figure up the uneven of the distribution of magnetic field along the circle direction of winding. So the 3D finite element method is the best choice when calculating short-circuit impedance.

\section{Analysis of Current Distribution}

In this paper, the high voltage winding is connected in parallel, then series connected with regulating winding, current excitation is applied at high voltage side when calculating short-circuit impedance from Figure 1. The problem of current distribution is analyzed in different conditions, the calculation results of 3D finite element method are shown in Table 3.

Table 3 shows that the high voltage parallel branch current in crossing is not much different and equal division when in the three conditions; current in semi-crossing is different and distribution uneven. The reason for this phenomenon is that: under the semi-crossing, the two low voltage winding impedances are different in the up and down two parallel branches, and the magnetic field is mutual affected. At last, a circle flowing the two low-voltage winding is emerged to counteract the imbalance of impedance.

\section{Conclusions}

In this paper, an axial dual-low-voltage split-winding transformer is selected as the research object, calculation model of the equivalent circuit and the leakage magnetic field is established. Analytical method, 2D and 3D finite element method are used to calculate the short-circuit impedance of transformer in different conditions, then get the following conclusions:

1) The error of 3D finite element and measured values is in $2 \%$. The maximum error of analytical method achieves $7.2 \%$. The 3D finite element method is more accurate than the 2D one and analytical method.

2) The current distribution can be accurately obtained by 3D field-circuit coupled finite element analysis method though the analysis of current distribution of high voltage parallel branch, then the precise short-circuit impedance is gained. All of these can be the reference frame in the short-circuit design of split-winding transformer.

\section{REFERENCES}

[1] S. S. Wang, Y. M. Li and Y. N. Guo, "Calculation of Short-circuit Impedance for Power Transformer with Coupling FEM Method of Magnetic Field and Circuit," High Voltage Engineering, Vol. 32, No. 11, 2006, pp. 11-14.

[2] B. R. Xie, Q. F. Chen and X. S. Li, et al., "Calculation of the Short-circuit Impedance of the Transformer with Split Types of Windings Using Three-dimensional FEM," High Voltage Engineering, Vol. 33, No. 6, 2007, pp. 97-101.

[3] K. F. Qu, W. Zhao and B. Jiang Bo, et al., "3D FEM Computation of Magnetic Field of Heavy Current Transformer with Shielding Coils,” High Voltage Apparatus, Vol. 45, No. 1, 2009, pp. 25-32.

[4] P. Zhou, D. Lin and W. N. Fu, et al., "A General Simulation Approach for Coupled Field-circuit Problems," IEEE Tans. on Magnetics, Vol. 42, No. 4, 2006, pp. 1051-1054. doi:10.1109/TMAG.2006.871374

[5] S. Kanerva, S. Seman and A. ArkkIio, "Inductance Model for Coupling Finite Element Analysis With Circuit Simulation,” IEEE Tansactions on Magnetics, Vol. 41, No. 5, 2005, pp. 1620-1623.

[6] B. R. Xie, Q. F. Chen and C. H. Kang, et al., "Modeling and Impedance Parameter Design for Multi-winding Transformer Based on Combined Field-circuit Coupled Method," Proceeding of the CSEE, Vol. 29, No. 9, 2009, pp. 104-111.

[7] F. X. Han, Y. Li and X. Sun, et al., "Calculation of Leakage Magnetic Field and Short Circuit Impedance of Power Transformer," Transformer, Vol. 47, No. 10, 2010, pp. 9-12.

[8] J. M. Wang, J. G. Jia and L. R. Liu, et al., "Research on Numerical Simulation of Three Dimensional Leakage Magnetic Field and Short Circuit Impedance of Phase-Shifting Rectifier Transformer,” Transformer, Vol. 46, No. 4, 2009, pp. 1-5. 